\title{
SACERDOTE ESPOSO
}

DOI: https://doi.org/10.52039/seminarios.v62i216.153

SANTIAGo Bohígues FERnÁNDEZ*

INTRODUCCIÓN

En este artículo he querido recopilar un escrito de D. Raúl Berzosa, obispo de Ciudad Rodrigo, donde comenta el Cantar de los Cantares aplicado al sacerdote como esposo ${ }^{1}$. Se encuentra abundante bibliografía sobre el sacerdote como cabeza, pastor y siervo, pero resulta mucho más difícil encontrarla como sacerdote esposo o reflexiones teológicas sobre la dimensión esponsalicia del ser sacerdote, que la Exhortación Pastores dabo vobis ha formulado con claridad: «que los candidatos conozcan y sigan a Jesús, preparándose a celebrar y vivir el sacramento del orden que los configura con Cristo cabeza y pastor, siervo y esposo de la Iglesia» (PDV 3 ).

Al publicar este artículo busco destacar esta dimensión tan importante de la espiritualidad del sacerdote, que a veces no se tiene en cuenta y que es uno de los temas más preferidos y originales de san Juan Pablo II.

\section{FUNDAMENTO BÍBLICO}

El sacerdote esposo que mira a su comunidad parroquial como verdadera esposa, en una verdadera relación de amor, encuentra en las cartas paulinas y en el Cantar de los Cantares una verdadera fundamentación bíblica; muchos textos pueden iluminar la identidad y el ministerio sacerdotal: «Al final, todo se reduce a la fe, esperanza y amor. Pero lo mayor de todo es el amor» (1 Cor 13, 13).

Muchos místicos han hablado del desposorio espiritual que se puede aplicar al sacerdote en su ministerio pastoral; muchos textos de san Juan de la Cruz se pueden aplicar a la vida del sacerdote: «Es un alto estado y unión de amor en que, después de mucho ejercicio espiritual, suele Dios poner al alma; lo llaman desposorio espiritual con el Verbo Hijo de Dios» (Cántico espiritual 14,2).

La última parte de este artículo la voy a dedicar al comentario que D. Raúl Berzosa dedica al libro del Cantar de los Cantares; este libro de la Sagrada

* Sacerdote de la diócesis de Valencia. Director del Secretariado de la Comisión del Clero en la Conferencia Episcopal Española.

1. R. Berzosa, Sacerdote Esposo. Relectura del Cantar de los Cantares, Burgos 2000, 9. 
Escritura habla de una verdadera experiencia de amor, de un amor vivido por el pueblo de Israel, por la Iglesia y por cada cristiano y, cómo no, por cada sacerdote. En la vida y en el ministerio de los sacerdotes el amor traducido en caridad pastoral, da luz a todo lo que él es y vive en su actividad pastoral ${ }^{2}$.

\section{REFLEXIÓN TEOLÓGICA}

La vida de comunión del sacerdote con Cristo y la entrega al servicio de los hombres en el Espíritu Santo si se viven en fidelidad, transforma existencial su vida a Cristo en amor: «Es preciso que los hombres vean en nosotros ministros de Cristo y dispensadores de los misterios de Dios. Por lo demás, lo que en los dispensadores se busca es que sean fieles» (1 Cor 4, 1-2).

La fidelidad exige una valoración continua del carisma conferido por el sacramento del Orden: «Por eso te amonesto que hagas revivir la gracia de Dios que hay en ti por la imposición de mis manos. Que no nos ha dado Dios espíritu de temor, sino de fortaleza, de amor y de templanza. No te avergüences jamás del testimonio de nuestro Señor; antes soporta con fortaleza los trabajos por la causa del Evangelio, en el poder de Dios» (2 Tm 1, 6-8).

El presbítero debe esforzarse para ser fiel en sus opciones fundamentales, no por temor o por conveniencia, no por rutina, sino por un motivo de amor; la fidelidad sólo florece y crece en el amor. La fidelidad es el resultado de un amor que desafía al tiempo, venciendo su fragmentariedad y provisionalidad. Don total de toda la vida a Dios y a los hermanos, sin reservas y sin límites de tiempo es madurez cristiana.

Ningún sacerdote puede pensar en resolver sus problemas como si fuera sólo suyo, en caso de dificultad. Desde el momento en que libre y responsablemente ha percibido la voluntad de Dios, que le llama, y se ha comprometido a cumplirla, su destino no le pertenece ya solamente a él, sino que está vinculado al plan de amor de Dios en Cristo; tenerlo en cuenta, confiar en Dios y en su ayuda.

El sacerdote que se entrega a vivir en fidelidad su ministerio al servicio de Dios, a amar a los hombres en el amor de Dios, será un signo creíble del amor de Cristo hacia la Iglesia y del amor de la Iglesia hacia Cristo ${ }^{3}$.

San Juan de Ávila para explicar el sacerdocio de Cristo utiliza el simbolismo de los desposorios para significar la entrega absoluta en su ministerio; estas nupcias representa la superación del sacerdocio levítico: «Aquel oficio era sombra y casi nada en comparación del oficio sacerdotal de la nueva Ley, con el cual se consagra y recibe el mismo Hijo de Dios $»^{4}$. La antigua alianza era anuncio de

2. Cf. ibid., 10.

3. Cf. A. Favale, La relación del presbitero con Cristo, en Simposio: Espiritualidad del presbítero diocesano secular, Madrid 1987, 229-230.

4. Juan de Ávila, Tratado sobre el sacerdocio, en Obras completas III, Madrid 2000, 507. 
algo mucho más grande que había que venir: «y esto es lo que fue figurado, en el principio del mundo, cuando el justo Abel, pastor de ganados, ofreció a Dios sacrificio de su manada, el cual sacrificio fue acepto..., lo cual es figura de nuestro justo y soberano pastor, el cual dice de sí: Yo soy buen pastor. Y también es sacerdote» ${ }^{5}$.

El contenido de este sacerdocio no es algo exterior a él, sino que es el mismo «desposado y el modo de desposar» ${ }^{6}$. Toda la espiritualidad del sacerdote secular según el maestro Ávila arranca del significado sacerdotal que tiene la encarnación del Verbo; el sacerdocio de Cristo aparece como un desposorio con la humanidad por amor y sacrificio: «Así Jesucristo, siendo nuestras las deudas, tomolas por suyas y dionos lo que ganó y casóse con nosotros» ${ }^{7}$.

De igual modo, los sacerdotes por la participación en el sacerdocio de Cristo se han desposado con la misión de «encaminar las ánimas para el cielo. Sicut misit me Pater, et ego mitto vos» ${ }^{8}$. Los sacerdotes tienen tal amistad y trato con Dios que se puede decir que presencia en su ser, obrar y sentir todo el misterio del amor de Dios a los hombres ${ }^{9}$. Ellos ofrecen su «fragilidad y Dios su grandeza» ${ }^{10}$.

\section{COMENTARIO AL CANTAR DE LOS CANTARES}

Tus amores son deliciosos más que el vino; el aroma de tus perfumes es exquisito, tu nombre es un bálsamo que se esparce, por eso te aman las doncellas (Cant 1, 1-2).

Hay realidades que no cambian. No necesitan cambiar. Porque en ellas encontramos el sentido del tiempo y de la novedad absoluta. «Me has enamorado y cautivado. No sé vivir sin ti. ¡iTanto me has dado!! ¡iY aún busco más!! [...] No anhelo sólo tus umbrales: deseo entrar en Ti. No anhelo sólo tus dones: quisiera fundirme, en abrazo eterno y duradero, enTi, Jesucristo, respuesta y plenitud. Mi Señor y mi Dios, mi Salvador y mi Esposo ${ }^{11}$.

Que Él me bese con besos de su boca (Cant 1, 1).

La Trinidad entera se comunica: el Padre besa; la boca es el Hijo; el beso es el Espíritu Santo. Señor, Uno y Trino, te necesito. Deseo la gracia de experimentar tu Presencia, tus acciones, tus besos. [...] Bésame con tu Espíritu. Sólo entonces la unidad y el amor estarán consumados ${ }^{12}$.

5. Id., Audi filia, I, 783.

6. Ibid., I, 731.

7. Id., Sermón 6, II, 127.

8. Id., Pláticas, III, 438; cf. Carta 35, V, 219.

9. Id., Sermón 4, II, 88-104.

10. Id., Pláticas, III, 365-368.

11. R. Berzosa, Sacerdote esposo, 15.

12. R. Berzosa, Sacerdote esposo, 16. 
Arrástreme tras de ti; correremos (Cant 1,3).

Cuando el deseo del Amado es sincero, el propio Amado suscita en tu corazón la necesidad de la unión.

Desde la soledad sentida, desde las rupturas, los desgarros y las lágrimas. Salí sin familia ni amigos. Ligero, como nunca, de equipaje. Y me encontré con el Amado. No hubo palabras. Bastó una mirada. Y una invitación: no te detengas en pequeñas aventuras. Búscame en el hontanar de tus entrañas. [...] Sólo el amor descansa cuando en abrazo de Amor se funde para siempre.

El rey me ha introducido en sus recámaras, tú serás nuestro gozo y nuestra alegría (Cant 1,3).

El tiempo no es sólo ni principalmente medida cronológica. El tiempo reside en las vivencias fundantes del corazón. Sólo se vive realmente el tiempo vivido con el corazón. Y el corazón pertenece al Señor.Existen esperanzas y ansiedades, lágrimas y sonrisas, amores y desamores, búsquedas y encuentros. [...]Tú, Señor del tiempo y del espacio, de la infinitud y del acontecimiento, del corazón hecho a tu imagen, das sentido a todo, llenas todo, eres el Único.

Celebraremos tus amores más que el vino; con cuánta razón eres amado (Cant 1, 4).

Son necesarias las noches para valorar la luz. Son necesarias las crisis para sustentar nuestra vida en Él, único estable y duradero.

Servir al Señor de la luz desterrando sombras de muerte. Proclamar las hazañas del Dios de la vida y de la gloria. Resurgir de fondos indecibles curando los ojos del corazón para contemplar, en gratitud extasiada, la nueva luz de la mañana. Experiencias de personas y de un pueblo que renace.

Los hijos de mi madre se han vuelto contra mí (Cant 1, 6).

¿Es posible ser un desconocido para los hermanos de propia sangre? Sí, cuando llega un momento en el que la familia es, sobretodo, la de la fe. Somos signos de contradicción y extraños en nuestra propia casa.

Soy un extranjero para mis hermanos, un desconocido y un paria. Se han vuelto contra mí. Me han confinado al exilio. Sólo, por cantar la canción de mi Amado. Suena diferente a todo lo conocido. Abre horizontes y despierta conciencias. Canción que seduce hasta hacer del Amado tu único Esposo, tu único Señor, tu único Rey, tu único Tesoro.

Dime, Tú, a quien mi corazón ama, ¿dónde llevas a pastar el rebaño, dónde le haces reposar al mediodía? Para ya no andar más errante tras los rebaños de mis compañeros (Cant 1,7 ).

Somos una paradoja existencial: cuanta más memoria histórica almacenamos, mayor despojo se nos pide. Nuestra tarea, fundir nuestra memoria en Él, el Dios del pasado, del presente y de futuro. 
Escribe tu nombre en el libro de la Vida. Entrelaza lo que eres, sientes, piensas, dices o haces, siempre en Él. Tus vivencias, tus amigos, tus recuerdos, tus proyectos, las pequeñas o grandes cosas que has amado o encontrado en tu camino, fúndelas en Él. Porque al final, atravesando el vértigo purificador de las noches, sólo queda lo Suyo, y, en lo Suyo, todo lo tuyo.

Sigue las huellas de las ovejas y lleva a pacer tus cabritas junto al jacal de los pastores (Cant 1, 8).

¡Qué misterio insondable: llega un momento en el que el pastor, para crecer, tiene que seguir al rebaño!

Señor, único y eterno pastor. Tú nos amas a cada uno con amor personal, y nos conoces mejor que nosotros a nosotros mismos. Tú has escrito en lo profundo de nuestro ser cuál es el sentido al deseo de luz, amor y plenitud que anhelamos. Ayúdame a despojarme de todo, incluso del rebaño: no es mío. Tú me lo confiaste y te pertenece. Tú eres el guía, el camino y la meta. Tú Pastor de pastores, de quienes supieron, en fidelidad, conducir tus rebaños y dejarse conducir por ellos.

Mientras el Rey está en su recinto, mi nardo exhala su perfume (Cant 1, 12).

Cuando se ha encontrado la Vida, tan sólo en presencia del Amado parece que vivimos de verdad.

Tú eres Aquel a quien mi corazón ama. Eres mi hogar, mi cercado, mi recinto, la sala del banquete, la cuna y el altar. Sé muy bien de quien me he fiado. Y Tú me rodeas y seduces. Sacas de mi interior los mejores frutos. $Y$ los tomas y los haces tuyos. Concédeme la gracia de ser siempre sacramento, transparencia inmerecida de tu presencia amorosa.

Mi amado es para mí una bolsa de mirra que descansa en mis pechos (Cant 1,13).

Para encontrarle se necesita buscar donde su presencia se hace más fuerte y donde su amor espera con fidelidad y paciencia infinitas: el sacramento de la Eucaristía, el sacramento del Amor.

Ha llegado la hora. Ha llegado su hora. El esposo susurra: «Sube». El amor se va a consumar. Es el fin de la espera. Finalmente me he atrevido: los dos solos, frente a frente. Yo en mi cuerpo; Tú en un sagrario. Sacramento y mediación, Presencia y encuentro. Ahora sí: somos dos en uno, latiendo a corazón abierto, susurrando: «¿Me amas?». «Sí, Señor, Tú sabes que te amo». Tú me has amado primero y no dejas que el Amor se apague.

Qué bella eres, amiga mía, qué bella eres (Cant 1, 15).

La mayor locura de todo un Dios es haberse enamorado de una criatura.

¿Cómo puede la Belleza llamar bello a algo diferente a ella? ¿Qué fascinación y hermosura encuentra el Amado en la pequeña amada? ¿Qué pasión y 
locura se derrama en todo un Dios que amar desea? Amor de amistad, Amor de Esposo, Amor de Padre, Amor de hermano.

Gocémonos, Amado, y vámonos a ver en tu hermosura (Cant 1, 15).

Sólo en el Amor del Amado llegaremos a conocer nuestro radical secreto y el misterio profundo que somos.

Verme en tu hermosura y gozar plenitud al mismo tiempo. Sentirme en tu corazón y amar todo lo tuyo. Abandonarme en tu regazo y volver a sentir la inocencia primigenia. Transfórmame con tu gracia para vivir tu misma vida.

Yo soy el narciso de Sarón, el lirio de los valles (Cant 2, 1).

Hay que salir de uno mismo para encontrarse con el Dios Viviente, con el Dios de la Creación y de la Belleza que enamora.

Bendito el Creador, el Dios de lo grande y de lo pequeño. El Dios que todo lo envuelve, todo lo empapa, todo lo sustenta, todo lo recrea.

Bendito el Creador que no se cansa de esperar a que sus criaturas contemplen en su obra las huellas de su hacedor.

Bendito el Creador que, en su Hijo, mirándose, nos ha mirado, y, encarnándose, nos ha recreado.

A su sombra, deseé y me senté (Cant 2, 3).

Cuando el amor te envuelve, sientes la protección y la fuerza para seguir viviendo y amando. Y renacen la fe y la esperanza.

Bajo su potencia y su providencia, a su sombra de Altísimo, a su abrigo y en su manto, la noche y las tinieblas se disipan.

Nace un deseo: escóndeme en Ti, hazme tuyo, purifica todo lo que me separa de Ti. Hazme ver tu rostro. Déjame gustar tus delicias.

Yo estoy herido de amor (Cant 2, 5).

Cuando experimentabas algo del Dios Vivo, nada te lo puede borrar. Te marca para siempre.

Estoy herido de amor, estoy sangrando por el Amado. Me abrió la fuente de la Vida, esculpió un mensaje en mis entrañas.

Herida abierta, nadando entre luz y sombras. Deseo ardiente, que hace morir y renacer a un mismo tiempo.

Dulce llaga por donde entra la ternura de un Dios que sana y que me llama por mi propio nombre. Estoy herido de amor, y ni la herida ni el amor me pertenecen.

¡Levántate, amada mía, hermosa mía ven a mí! Porque ha pasado el invierno y brotan flores en las vegas (Cant 2, 11).

Es verdad: sin saber por qué, Él te agarra por entero y te renueva y te hace volver a recobrar la luz y la fuerza. Todo, cuando menos lo esperas.

Es una mañana de primavera. Detengo mis pasos en un jardín cualquiera. 
Cierro mis cansados párpados. ¡Ahora sí!: Me siento-Te siento fuera-dentro-arriba-abajo, Señor del espacio y del tiempo, de la primavera, de las sensaciones, y de la Vida.

En mi lecho por la noche busqué a aquel a quien mi corazón ama. Le busqué y no le encontré (Cant 3,1$)$.

La santidad y la perfección no se conquistan con los puños, ni con la sabiduría humana. Es vida donada. Su fuente originaria no está en nosotros.

La fe me lleva a ti, y también, el amor y la esperanza. Me abandono en $\mathrm{Ti}$, por Ti, contigo. Fe hecha don y tarea cotidiana. Fe alimentada en comunidad, abierta en gestos siempre nuevos de solidaridad. [...].

Tú eres lo importante. Tú eres el sentido, el principio y el final. Tú eres Alfa y Omega. Tú, mi Señor, mi Amado, mi Amigo, mi Plenitud.

En las calles y por las plazas, buscaré al que mi corazón ama (Cant 3,1$)$.

Dios no sólo está en las alturas sino en medio del mundo. Él es el corazón de lo creado y, al mismo tiempo, es más que todo lo existente. AÉl todo le pertenece.

¿Cómo encontrarte si Tú no te manifiestas? ¿Dónde buscarte si Tú no sales a nuestro encuentro? Tú eres todo y nada de lo que existe te abarca. Tú eres el corazón del mundo y la carne de todo hombre.

Eres espíritu encarnado y carne espiritualizada. Eres el inmanente y el trascendente, el dador y el mendigo. Eres tiempo y eternidad, el silencio y el poema. Eres la unidad y la trinidad, el origen y el fin.

Encontré al amor de mi alma: lo agarré y ya no lo soltaré (Cant 3,4$)$.

Cuando Dios pasa por tu vida, y te habla, su voz no puede ya ser olvidada, apagada o confundida con otras voces que no son la suya.

Me hablaron de Ti mis padres, me hablaron de Ti mis libros, me hablaron de Ti los púlpitos, me hablaron de Ti los rezos... ¡Tantos me hablaron de Ti...!

Un día me hablaste Tú, como Tú sabes hacerlo. Entonces, igusté la diferencia! Tú eres todo y diferente, personal y envolvente, Señor, Esposo, Hermano.

Tus ojos son palomas, tu pelo un rebaño de cabras, tus dientes un rebaño recién esquilado, tus sienes dos granadas, tu cuello la Torre de David, tus pechos dos crías de gacela (CC 4, 2-5).

La mirada de Dios no es como la de los hombres. Dios ve la hermosura interior de su criatura. Por eso a Él, sólo a Él, pertenecen el futuro y la última y decisiva Palabra.

Busco, Señor, en tus ojos todo aquello que Tú ves en mí. Busco, Señor, en tus manos todo aquello que Tú haces en mí. Busco, Señor, en tu corazón todo aquello que Tú sientes en mí.

Y lo busco, Señor, para ya no tener más ojos que los tuyos con qué mirar, más manos que las tuyas con qué obrar, más corazón que el tuyo con qué amar, más Vida que la tuya, más espíritu que tu mismo Espíritu. 
Me has enamorado, hermana y novia mía, me has enamorado con una sola de tus miradas (Cant 4, 9).

Hay que atreverse a devolverle lo que Él nos ha regalado, el Amor.

Te diría muchas cosas. Tantas cuantas el corazón me dicta. Hoy, aquí, sólo una: «Te amo y quiero serte fiel para siempre».

Eres jardín cerrado, hermana y novia mía; eres fuente sellada (Cant 4, 12).

El día más feliz de tu existencia es aquel en el que descubres que todo tu ser, lo que haces-sientes-piensas, es de Él. Y en Él sólo encuentra sentido y plenitud.

Amanece. Balbucea la luz. Con la luz la materia es consciencia. La consciencia es palabra. La palabra se hace llamada. La llamada presencia. La presencia eres TÚ.

Entra, amor mío, en tu jardín a comer de sus frutos exquisitos (Cant 4, 16).

Dios es tan celoso que sólo habla cuando somos capaces de acallar otras voces y otros amores.

Ya no sirve la palabra, ni el concepto, ni la imagen. No sirve nada de lo mío, porque ya no soy mío.

Habla Tú, Señor, o mejor, tómame, y sin decir nada, hazme tuyo, sólo tuyo.

Comed, amigos, bebed, embriagaos, mis amados (Cant 5,1 ).

El mayor misterio que nos ha dejado el Señor Vivo es su presencia real en el sacramento de la Eucaristía. Es la mayor y más cercana prueba de Amor de un Dios Amor.

Lo has repetido una y otra vez en la historia: nos tomas, nos bendices, nos partes y nos repartes. En el pan y en el vino te has quedado para siempre.

$Y$ tu cuerpo se prolonga en el nuestro. Y nuestro cuerpo se hace tu cuerpo. $Y$ todo queda transformado.

El tiempo ya no es sólo tiempo, ni la materia sólo materia, ni la historia sólo historia. Todo nos habla de Ti.

La Eucaristía se hace vida, la vida acción de gracias, y la acción de gracias alabanza. Al final, todo es tuyo. Sólo Tuyo, mi Dios y mi Amado.

Yo duermo, pero mi corazón vela (Cant 5, 2).

La oración incesante es la mayor de las gracias que el Señor puede concedernos mientras existimos.

¡Qué suerte mantener tu nombre, día y noche, en mis labios y en mi corazón!

Te has convertido en mi gran tesoro. No deseo más. Sólo vivir en Ti.

Escuchar tu voz en mi nada. Experimentar tus caricias en mis noches. Sanar mis heridas pasadas y presentes. Silenciar mi agitado corazón.

No es abandonar el mundo que Tú has creado. Es latir contigo, dentro del universo, y más allá de lo visible. 
¿A dónde fue tu amado? Queremos buscarlo contigo (Cant 6, 1).

Fe es ver la vida con sus mismos ojos; sentir con su mismo corazón; hacer las cosas en la vida con sus mismas manos.

Orar como tú oraste; con lo que tú oraste; por lo que tú oraste; donde tú oraste; cuando tú oraste; con quienes tú oraste; para lo que tú oraste; para quien tú oraste.

Amar como tú amaste, con lo que tú amaste, por lo que tú amaste, donde tú amaste, a quien tú amaste. [...]

Tú eres el Todo y todo para mí. Tú eres el Todo y todo para mí. Tú eres el viviente: nada existe fuera de Ti, sólo existo para Ti.

Sin saberlo, me encontré en la carroza con mi príncipe $(C C 6,11)$

La fuerza del peregrino no está en él. Le viene de la espera en caminos nuevos que aún debe recorrer.

Al otro lado me esperas entre mármoles sagrados. Al otro lado, en tu barca, pero siempre al otro lado. Mi vista se pierde azul contemplándote lejano.

Del otro lado me llamas, y me encuentro acobardado por rumores de mi carne: ¡Es mi sitio; no lo cambio! Te estoy oyendo y oyendo: «Al otro lado, al otro lado».

A la puerta hay mil frutas deleitosas que he guardado, mi amado, para $\mathrm{Ti}$ (Cant 7, 14).

Sepamos dar gratis lo que hemos recibido gratis.

Un día cualquiera sentí miedo a descubrirte como amor y carne al mismo tiempo. Dios y hombre fundidos en una única existencia. ¿Qué vale la vida sin Ti? Desvélate en tu Espíritu. Toma mi nada. Borra lo que no es tuyo. Sí, hasta el verso y la palabra si de Ti no hablaran. En tu Palabra, la palabra. En tu eternidad, la historia. En tu presencia silenciosa, el sentido y la fuerza para seguir viviendo.

Yo soy de mi Amado y hacia mí tiende su deseo... porque el Amor es fuerte como la muerte (Cant 7,$11 ; 8,6)$.

Al final, la verdadera sabiduría consiste en descubrir que Él es todo y que todo, en nuestra vida, tendía hacia Él.

Yo soy de mi Amado. Lo que pienso y lo que siento, lo que tengo y lo que hago. Y todo en mí tiende a Él. No importan los desgarros, los desvíos o los sueños. Él, desde siempre, ha caminado conmigo, me ha instruido internamente, me ha despertado al amor y ha marcado el horizonte de mi vida.

Entonces, Tú me enseñarás (Cant 8, 2).

El renacer nunca es un momento puntual de una vez para siempre. Es un punto de partida hacia una nueva vida.

Misericordia que crea vida y hace posible un nuevo nacimiento. Y nos devuelve la esperanza. Misericordia que tiene nombre propio: el Dios de Jesucristo. $Y$ 
corazón y rostro humanos: Jesús el Señor. Misericordia que nos mantiene despiertos, en vigilia solidaria. Misericordia con entrañas de madre. Misericordia que sólo es propia de un Dios inmanente-trascendente, encarnado y eterno.

Ponme como un sello sobre tu corazón (Cant 8, 6).

Un cristiano maduro integra los contrarios y vive la dialéctica humano-divina: nacer-renacer; muerte-vida; hombre-Dios.

¡Es posible renacer! ¡Es posible la transformación profunda! ¡Mente, corazón y espíritus nuevos! Desnudarse de lo nuestro y revestirse de lo suyo. Cambiar personas y estructuras. Hacer posible la utopía encarnada. El Espíritu enamora. El Espíritu fecunda. El Espíritu inunda todo. Sin perder identidad ni conciencia, rompiendo moldes finitos, abriéndote a la inmensidad de lo infinito.

Yo seré para él mensajera de paz (Cant 8,10$)$.

Purifica mis deseos, silencia mi corazón, cura todas mis heridas, lléname de tu amor.

Estoy en silencio. Todo está en silencio. Todo es silencio. Todo duerme. [...] Siento nublarse mi vista, mi corazón y mi consciencia. Escribo sobre el suelo. He necesitado la pobreza, la desnudez y el silencio para dejar que me hables, para dejarse ser lo que Eres.

Mi viña es sólo para mí (Cant 8,12$)$.

¿Quién o qué nos separará del amor de Dios?

Seguir tus pasos, vivir tu presencia, rasgando miedos. Desde lo más hondo una extraña sensación. Desde lo más hondo una extraña sensación: encontrar tu estilo, tus Palabras, tu Amor y tu Vida, sin luchar ni merecerlo. Puro don, pura gracia. Gratuidad que exige respuesta. 